\title{
Loss of Power Problem
}

National Cancer Institute

\section{Source}

National Cancer Institute. Loss of Power Problem. NCI Thesaurus. Code C63052.

Problem associated with the failure of primary power supplied by the facility. 